\title{
Perfil ético del docente universitario desde la valoración de estudiantes de educación
}

\author{
Ethical Profile of the University Teacher from \\ the valuation of education students
}

\author{
Pedro Emilio Ventura Sosa ${ }^{a}$ ORCID: ORCID: 0000-0001-8636-9703
}

Recibido: $17 / 01 / 2020 \cdot$ Aprobado: 19/09/2020

\begin{abstract}
Cómo citar: Ventura Sosa, P. E. (2021). Perfil ético del docente universitario desde la valoración de estudiantes de educación.
\end{abstract} Ciencia y Educación, 5(1), 113-129. https://doi.org/10.22206/cyed.2021.v5i1.pp113-129

\section{Resumen}

Este estudio, de tipo interpretativo y diseño cualitativo, se propuso comprender, desde la valoración de un grupo de estudiantes de la carrera de Educación, los rasgos que reconocen importantes en el perfil ético de un docente universitario e interpretar las actuaciones que consideran éticas y antiéticas. Fueron sistematizados los registros de opiniones de 39 estudiantes, a través de foros virtuales, un grupo focal y las anotaciones en un registro anecdótico del docente-investigador. El análisis de la información recabada se realizó a partir de categorías emergentes surgidas de los argumentos de los estudiantes. Los resultados destacan como rasgos positivos del perfil ético de un docente universitario: puntualidad, cordialidad, buen trato, coherencia entre el decir y hacer, justicia, solidaridad, democracia y actualización. Los rasgos no deseados incluyeron: responder groseramente, mostrar preferencias, mentir y hacer insinuaciones amorosas. El estudio permitió describir actuaciones éticas de impacto positivo que afianzarían el perfil docente deseable para su formación.

Palabras clave: ética; ética del docente; competencias del docente; responsabilidad del docente; personal académico docente.

\begin{abstract}
This study of an interpretive type and qualitative design, aimed to understand, from the valuation of a group of students of the Education major, features that they recognize as important in the ethical profile of a university teacher and to interpret which actions they consider ethical and unethical. The records of 39 students' opinions were systematized through virtual forums, a focus group, and an anecdotal record of the researcher teacher. The analysis of the information collected was carried out using emerging categories that resulted from the students' arguments. The results highlight as positive features of the ethical profile of a university professor: punctuality, cordiality, and good treatment, coherence between saying and doing, justice, solidarity, democracy, and updating. Unwanted traits included: responding rudely, showing preferences, lying, and making amorous insinuations. The study made it possible to describe ethical actions with a positive impact that will strengthen the desirable teaching profile for their training.
\end{abstract}

Keywords: Ethics; teacher ethics; teacher competencies; teacher responsibility; academic teaching staff.

a Universidad Abierta para Adultos (UAPA), República Dominicana. Correo-e: pedroventura@uapa.edu.do 


\section{Introducción}

A lo largo de la historia la figura del docente ha adquirido diferentes significados y valoraciones, que ha venido situándolo como un estandarte, un referente y un ejemplo de actuación, sin importar la dimensión desde la que se le aprecie: personal, laboral, social, entre otras. En algunas culturas se asume al docente como una figura con cualidades extraordinarias, en otras, se le reconoce como el segundo padre o tutor de los estudiantes. Estas perspectivas han permeado el papel social asignado a los docentes, trascendiendo de un compromiso laboral a una misión o vocación de servicio orientada a humanizar las generaciones y hacer posible la perpetuación de la cultura y el conocimiento.

Lo descrito anteriormente ha generado un interés constante por realizar estudios acerca del perfil ético de los docentes, en diferentes niveles de formación. Se entiende por perfil ético del docente, al conjunto de cualidades profesionales y morales que evidencian una actuación apegada a los principios y normas de aceptación social e institucional y que pueden servir de referentes a los estudiantes que forma (Ministerio de Educación de la República Dominicana, 2015).

Las entidades de educación superior contemplan en sus reglamentaciones las conductas deseadas para su personal docente, específicamente, las responsabilidades que deben asumir con el estudiantado, la institución y la comunidad universitaria en general. Sin embargo, estas conductas no siempre satisfacen las expectativas de los estudiantes, quienes esperan en sus docentes modelos de actuación dignos de ser replicados.

En los estudiantes universitarios que se forman para docentes en la Universidad Abierta para Adultos (UAPA) de la República Dominicana, se genera gran inquietud en relación con los retos, expectativas y desafíos que enfrentarán durante su ejercicio profesional. La correcta actuación ética no es la excepción, de ahí que siempre evalúan el proceder de sus docentes, buscando referentes de conductas éticas que fortalezcan su formación. En otras palabras, de los formadores de maestros, además de lograr en sus estudiantes las metas educativas contempladas en los programas de sus asignaturas, se espera que eduquen con sus actuaciones, ya que como señala Santos (2018), "los alumnos aprenden de aquellos profesores a los que aman" (p. 35).

Los docentes, como profesionales cuya labor se encamina a generar cambios en la manera de pensar, actuar y convivir de otras personas, se encuentran vinculados de manera inevitable a situaciones que atañen a la ética y a la moral. De acuerdo con Crisol y Romero (2014) "La ética no es algo que existe de entrada, es una exigencia difícil, que nunca se conquista de manera definitiva. Si la moral tiene por cuestión básica el qué debo hacer, la ética específicamente apunta al ¿por qué debo hacerlo?” (p. 26).

Estos aspectos afianzan la responsabilidad del docente universitario como un agente motivador y un propulsor de los cambios sociales, a través de su capacidad para transformar su entorno y enriquecer la condición humana de sus estudiantes (Panza, 2020).

A partir de lo planteado surgió la motivación por realizar una investigación que permitiera establecer una aproximación al perfil ético del docente universitario, desde la perspectiva de un grupo de educadores en formación y mostrar la sistematización de esa experiencia docente e investigativa. Para ello, se asumió como ámbito de acción las facilitaciones desarrolladas en la asignatura Ética Profesional de los Docentes que oferta la Escuela de Educación de la Universidad Abierta para Adultos, para realizar el levantamiento de informaciones durante los dos últimos cuatrimestres del año 2019.

\section{Marco teórico}

La actuación de los docentes es un tema que se ha estudiado ampliamente en distintos escenarios en los que estos desempeñan su labor. Para efectos de esta investigación, se presentan algunos antecedes de estudios vinculados al perfil ético del docente universitario, visto desde la perspectiva de los estudiantes. Destaca un estudio realizado por Chávez y Benavides (2011) en la Universidad Nacional Autónoma de México, titulado "Los profesores universitarios: Entre la exigencia profesional y el compromiso ético-social”, en el que 
se concluye que el compromiso ético del docente se asume fundamentalmente en el proceder respecto a los estudiantes, al ver en ellos los primeros beneficiarios o perjudicados de la puesta en práctica de los cambios educativos que el profesor debe representar.

Otro estudio similar, que alude al perfil ético del docente en la educación superior, fue el realizado por Martín et al. (2014), en el que indagaron acerca de las cualidades que debe poseer el perfil del profesor universitario ideal, desde la perspectiva de los estudiantes preuniversitarios de cuatro universidades españolas. Los consultados en el estudio señalaron que prefieren un profesor universitario que destaque en ciertos aspectos profesionales más que personales, en contraposición con otros trabajos, sin embargo, resalta la valoración de cualidades como: cercano, ameno, justo y paciente. Dentro de las cualidades menos valoradas se encuentran: disciplinado, exigente y entusiasta.

Por otro lado, el trabajo realizado en la Universidad del Desarrollo en Chile, por Villarroel y Bruna (2017), los autores señalan que, desde la perspectiva de los estudiantes consultados, la competencia más esperada fue la accesibilidad, entendida como la cercanía, empatía, flexibilidad, humildad y disponibilidad, seguida por estar actualizados en su disciplina.

Podría afirmarse que el contexto e idiosincrasia de los estudiantes inciden en la manera en que valoran las cualidades del docente universitario como referente en su formación, evidenciándose que, en el contexto latinoamericano, a diferencia del europeo, dan más importancia al trato cercano entre el profesor y el alumnado. Sin embargo, la responsabilidad, como una competencia blanda en el docente, es un aspecto muy considerado en su desempeño (Rodríguez, 2020).

En referencia al contexto nacional, Belando y Tavárez (2017), en su investigación respecto al perfil de los docentes en la educación universitaria de República Dominicana, concluyeron que éstos evidencian necesidades y limitaciones tanto en lo personal como en lo institucional y reconocen los retos actuales para el cambio. Además, destacan que tienen buena relación con los estudiantes, poseen valores éticos, son responsables, limpios, puntuales, entusiastas y muestran compromiso social.

La docencia universitaria es una actividad profesional que supone la puesta en marcha de una serie de acciones intencionadas y planificadas, ejercida por un profesional con pleno dominio de un área académica o técnica, con la finalidad de facilitar y promover el logro en un grupo de estudiantes de los saberes, destrezas, competencias y habilidades que se contemplan en el plan de estudio de la carrera que cursan. En ese sentido, el docente universitario en su carácter específico de profesional y especialista de una rama del saber cumple varias funciones en el seno de una comunidad académica, para lo cual se le exige una sólida formación de base, experiencia en el área que enseña y constante capacitación en el ámbito disciplinar y metodológico, impulsando así la calidad de los aprendizajes en sus estudiantes y el prestigio de la institución en la que labora. (Alix, 2017)

De allí que la docencia a nivel superior se entiende como una actividad que implica la contratación de profesionales de alta cualificación, para encaminar procesos formativos que logren el desarrollo de competencias en los estudiantes en correspondencia con el perfil de egreso de cada carrera. De acuerdo con Zepeda y Hernández (2020) "uno de los determinantes principales de la calidad de la Educación Superior para el estudiantado es la función docente, esto significa valorar un profesor de calidad" (p. 3).

En relación con los planteamientos anteriores, la labor del docente es vital para el logro de las metas educativas. En ese sentido, se requiere de profesionales con alta cualificación, es decir, se exige un perfil notable para encaminar la misión formadora que demanda la sociedad actual. Al respecto, Pérez (2019) reflexiona acerca de las nuevas demandas en cuanto a la formación cognitiva y emocional de los ciudadanos, que les permita actuar con sensatez y autonomía en la toma decisiones. El docente debe promover que el conocimiento sea visto como sabiduría, para dar respuestas más allá de los requerimientos utilitarios de la sociedad globalizada. Este autor refiere de manera más específica que: 
La sabiduría corresponde ya a otro nivel y puede considerarse como la utilización de los mejores recursos cognitivos y socioemocionales de los que dispone el sujeto para el gobierno de su propia vida como persona, ciudadano y profesional. Implica inevitables opciones de valor y responde fundamentalmente a preguntas éticas y teleológicas ¿para qué?, ¿hacia dónde?, ¿qué merece la pena? (Pérez, 2019, p. 5)

El perfil del docente universitario, además de la formación en el área que enseña, debe poder verificarse en su desempeño, a partir de rasgos éticos que sirvan de referente a los profesionales en formación que atiende, especialmente en el caso de los formadores de maestros. Al respecto, Ortiz (2020) plantea que:

... se debe reflexionar con respecto a nuestras funciones como docente y ofrecer diferentes alternativas que permita al estudiante tener un abanico de oportunidades al momento del proceso de enseñanza y aprendizaje, con la oportunidad de repotenciar la capacidad de razonar, argumentar y desarrollar habilidades que favorezca la convivencia entre el docente y el estudiante. (p. 341)

En ese mismo sentido, Santos (2018) apunta que la educación tiene dos pilares, uno crítico y otro ético, porque si no, a través de las escuelas y las universidades estaríamos convirtiendo a la sociedad en una selva sofisticada donde el más fuerte domina y destruye al más débil.

Del mismo modo, Merellano et al. (2016) destacan que:

El buen docente universitario necesita poseer características que transiten entre las habilidades pedagógicas, humanas e ideológicas, enfatizando en todo momento su accionar en y desde el aprendizaje, a través de un proceso de enseńanza pensado en el estudiante que está formando. (p. 950)

Los autores anteriores coinciden en que los docentes universitarios deben evidenciar una mixtura de cualidades que abarcan el ámbito disciplinar, metodológico, institucional y axiológico, con miras a lograr la formación de ciudadanos competentes y comprometidos consigo mismos, su familia y la sociedad en general.

En UAPA, contexto donde se desarrolló esta investigación, la institución ha declarado su compromiso por "mantener una planta de facilitadores altamente capacitados y actualizados, comprometidos con la institución valorados por la comunidad universitaria y por la sociedad en su conjunto" (UAPA, 2009 p. 27). Para ello, ha definido claramente el perfil del docente que necesita, y así lograr la concreción de su Modelo Educativo por Competencias Centrado en el Aprendizaje (MECCA), en el cual se ha establecido la definición de lo que se considera un facilitador, con énfasis en sus funciones claves:

Se denomina facilitador al profesional cuya labor en el seno de UAPA consiste en coordinar, orientar, guiar y evaluar el proceso de aprendizaje de una asignatura determinada, elaborar programas de asignaturas, producir materiales didácticos y guías de estudio, elaborar ítems de evaluación y participar de los proyectos de investigación y extensión que se lleven a cabo. (p. 3)

En alusión al perfil del docente, la Universidad ha establecido en su Reglamento de Facilitadores y Carrera Docente (UAPA, 2014), que se debe evidenciar lo siguiente:

a) Respeto hacia los estatutos y reglamentos de la UAPA.

b) Responsabilidad en el ejercicio de sus funciones docentes.

c) Respeto hacia los juicios y valoraciones externados por los participantes. ${ }^{a}$

d) Cordialidad, humildad y tolerancia en sus relaciones interpersonales.

e) Sensitivo a las necesidades de los participantes.

f) Identificado con los principios y leal a los valores, misión y visión de la Institución.

g) Empático, capaz de identificarse y ponerse en las situaciones de los participantes.

h) Innovador, promotor de cambio y capaz de mejorar permanentemente su acción docente.

i) Manifiesta disposición y creatividad para integrarse a las labores extensionistas de la UAPA.

a. Por la modalidad de la UAPA, la cual ofrece formación a distancia virtual, se promueve el aprendizaje autónomo guiado por el docente, por lo que se utilizan los términos facilitador y participantes para aludir a los maestros y estudiantes. 
Otra institución de educación superior de la República Dominicana que deja claro en sus normativas que el perfil de sus docentes debe considerar valores éticos y morales; es el Instituto Tecnológico de Santo Domingo (INTEC, 2016), el cual contempla que el personal académico, incluyendo a los profesores, debe establecer una relación positiva con el estudiantado, cimentada en el respeto por las posiciones ajenas y gran capacidad de diálogo. Así mismo, el acatamiento a los valores, la integridad e imagen del Instituto, cuidando en todo momento de preservar, por medio de su comportamiento y actitudes, el desarrollo de su quehacer y el prestigio institucional.

El trabajo del docente universitario implica grandes desafíos en los momentos actuales, debido a los cambios que se han venido adoptando en el perfil de los profesionales que les corresponde formar, con la introducción de constantes innovaciones en su praxis que les permita responder a las exigencias de la sociedad postmoderna. Es decir, que el docente de la Educación Superior debe asumir nuevas estrategias en su relación con los estudiantes que le faciliten responder a la transformación social, económica, cultural y tecnológica de la sociedad (Rubio y Olivo, 2020).

Para lograr un desempeño de excelencia en la docencia superior, donde el énfasis sea la formación integral de los estudiantes, es claro que el profesional que pretenda enseñar debe tener pendiente que, más allá de las competencias disciplinares que promueva en sus alumnos, debe considerar su actuación como un elemento ejemplificador. Al respecto, Aguirre y De Laurentis (2016) consideran que:

La buena enseñanza no atañe exclusivamente a una sólida formación académica y profesional, sino también a aspectos morales que inciden favorablemente en el aprendizaje. Los valores morales que los estudiantes perciben en sus profesores memorables generan un espacio de análisis que nos permite vislumbrar aspectos de la docencia del Nivel Superior corridos de la mirada tecnocrática, y poco tenidos en cuenta en la práctica docente. (p. 143)

De acuerdo con los autores anteriores, el quehacer del docente universitario es complejo, ya que en sus tareas convergen diferentes aristas vinculadas a su relación con los estudiantes, como ejes principales y razón de ser de la misión docente, y con sus compañeros de labores.

De allí que el trabajo colaborativo sea una de las competencias clave en el profesional actual, al mismo tiempo que tiene implicaciones institucionales y desde el punto de vista de la propia disciplina profesional que se enseña. En la tabla 1 se recogen algunas de esas implicaciones:

Tabla 1

Implicaciones de la labor del docente universitario

\begin{tabular}{|c|c|c|c|}
\hline Con sus alumnos & Con sus pares & Con la institución & Con su disciplina \\
\hline $\begin{array}{c}\text { Conoce sus necesidades } \\
\text { formativas y las asume en su } \\
\text { plan de docencia. }\end{array}$ & $\begin{array}{c}\text { Se involucra en actividades } \\
\text { que impliquen compartir } \\
\text { experiencias. académicas. }\end{array}$ & $\begin{array}{c}\text { Comprende su filosofía y la } \\
\text { asume a través del modelo } \\
\text { pedagógico. }\end{array}$ & $\begin{array}{c}\text { Domina en alto nivel lo que va } \\
\text { enseñar. }\end{array}$ \\
\hline $\begin{array}{c}\text { Diseña estrategias didácticas } \\
\text { en correspondencia con sus } \\
\text { posibilidades de Aprendizaje. }\end{array}$ & $\begin{array}{c}\text { Forma parte de redes de } \\
\text { aprendizaje. }\end{array}$ & $\begin{array}{c}\text { Participa en los programas de } \\
\text { formación continua. }\end{array}$ & $\begin{array}{c}\text { Investiga de manera permanente } \\
\text { y difunde los resultados. }\end{array}$ \\
\hline $\begin{array}{c}\text { Ofrece tutorías y apoyo de } \\
\text { manera focalizada. }\end{array}$ & $\begin{array}{c}\text { Se inserta en proyectos } \\
\text { conjuntos de investigación. }\end{array}$ & $\begin{array}{c}\text { Se adhiere a las políticas } \\
\text { proyectos que eleven el } \\
\text { prestigio académico. }\end{array}$ & $\begin{array}{c}\text { Participa en eventos científicos } \\
\text { relacionados a su área formativa } \\
\text { y docente. }\end{array}$ \\
\hline
\end{tabular}


Así, para el docente universitario además de la disciplina que enseña este debe constituirse en un referente para sus estudiantes, donde prevalezca la promoción implícita y explícita de aspectos relacionados con su actuación, es decir, que se convierta en un ejemplo a seguir en cuanto a desarrollar la disposición, el compromiso, la creatividad y la pasión por su desempeño profesional y ciudadano (Colina y Vargas 2018).

En esa línea de actuación, en la que el docente puede ser visto como un referente, el componente ético y axiológico es considerado como relevante, ya que los valores, más que enseñarse, se modelan a partir del proceder de las personas. Las implicaciones éticas deben ser consideradas como un aspecto relevante que, "ayuden realmente a cada individuo a construirse de manera singular y creativa, a construir los recursos cognitivos y emocionales más poderosos para afrontar la complejidad y la incertidumbre" (Pérez, 2019, p. 8).

En el caso de los docentes formadores de maestros el compromiso es mayor, ya que sus estudiantes, además de las competencias propias del área en que estudian, pueden asumir algunas actuaciones como referentes para transferirlas en su ejercicio profesional futuro. "Se enseña con la palabra, pero también con el ejemplo, la indumentaria, el diálogo, la relación autoritaria o democrática, etc. De tal modo que, no hay manera de que la enseñanza escape de la transmisión de valores" (Crisol y Romero, 2014. p. 27).

En el contexto de las universidades los docentes enfrentan disyuntivas éticas que ponen en confrontación muchas de sus actuaciones vinculadas a las directrices institucionales, el vínculo con los estudiantes y el propio crecimiento profesional del docente. Para Chávez y Benavides (2011), "la formación ética se concreta mediante las acciones diarias del profesor; por esta razón, la dimensión moral de la docencia universitaria debe ser reivindicada” (p. 6).
De acuerdo con Quintana (2016), se enfatiza en que el reto del docente formador de formadores consiste en desarrollar competencias para que sean "profesionales responsables, con principios éticos, capaces de utilizar el conocimiento científico como elemento transformacional de su entorno social, económico, ambiental y cultural" (p. 154).

Queda claro entonces, que el docente universitario está inmerso en un contexto educativo complejo, que le demanda diversas competencias y habilidades, pero también, satisfacer un perfil ético y valorativo que le permita favorecer la formación integral de sus estudiantes, lograr su propio desarrollo y satisfacción profesional y personal, además de contribuir a la consecución de los objetivos académicos de la institución en la cual labora.

\section{Metodología}

Este estudio, de tipo interpretativo y enfoque cualitativo (Denzin y Lincoln, 2012), es el resultado de la sistematización de informaciones valorativas proporcionadas por un grupo de estudiantes, en el marco de las actividades de aprendizaje de la asignatura de Ética Profesional de los Docentes, que se ofrece en la carrera de Educación de la UAPA. Para fines de delimitación, se tomaron en cuenta las facilitaciones de dos grupos que cursaron la referida materia durante los períodos 2019-2 y 2019-3.

Esos grupos fueron seleccionados debido a que eran los únicos matriculados para cursar la asignatura Ética Profesional de los Docentes durante los referidos períodos académicos. Se asumieron "las actuaciones éticas y antiéticas" en el ejercicio profesional del educador, como conceptos claves que guiaron el estudio, porque forman parte de los contenidos contemplados en el programa de la asignatura. 
El estudio se encaminó a la consecución de los siguientes objetivos:

1. Comprender, desde el punto de vista de un grupo de estudiantes de la Licenciatura en Educación, los rasgos más importantes del perfil ético de un docente universitario.

2. Caracterizar, según los estudiantes y su experiencia, las actuaciones que consideran antiéticas en el proceder de un docente universitario.

3. Interpretar las experiencias de los estudiantes que describan actuaciones éticas de docente que han impactado positivamente en su formación.

Para la realización de la investigación, se contempló el enfoque cualitativo por considerarlo más adecuado para los objetivos antes planteados, a través de la realización de grupos focales y foros abiertos que permitieron recoger las informaciones pertinentes para tales fines. En la presentación de los resultados se sustituyeron por números y letras, los nombres de los estudiantes y docentes involucrados como garantía de privacidad.

Se ha asumido un diseño cualitativo porque se busca comprender los testimonios y argumentos personales sobre el fenómeno en cuestión, para lo cual se recogieron informaciones a partir de opiniones y planteamientos de los estudiantes a través de foros virtuales, grupos focales y las anotaciones del registro anecdótico del docente-investigador (Baena, 2017). La investigación es naturalista, ya que se presentan las informaciones tal cual fueron recolectadas en el contexto en que se produjeron (Hernández, Fernández y Baptista, 2014).

El grupo que participó en el estudio estuvo conformado por estudiantes de la carrera de Educación, en las menciones de: Educación Inicial, Primer Ciclo de Primaria, Ciencias Sociales, Lengua Española, Lenguas Extranjeras y Matemática-Física. Se trabajó con toda la población de los dos grupos antes mencionados para un total de 52 alumnos, a los cuales se solicitó ofrecer sus respuestas hasta una fecha determinada en la plataforma virtual de la Universidad, de modo voluntario, y una vez concluido el plazo establecido se cerró el proceso, habiéndose recibido respuesta de 39 estudiantes, tal como se muestra en la figura 1 :

Figura 1

Participantes por Carrera

Participantes por Carrera

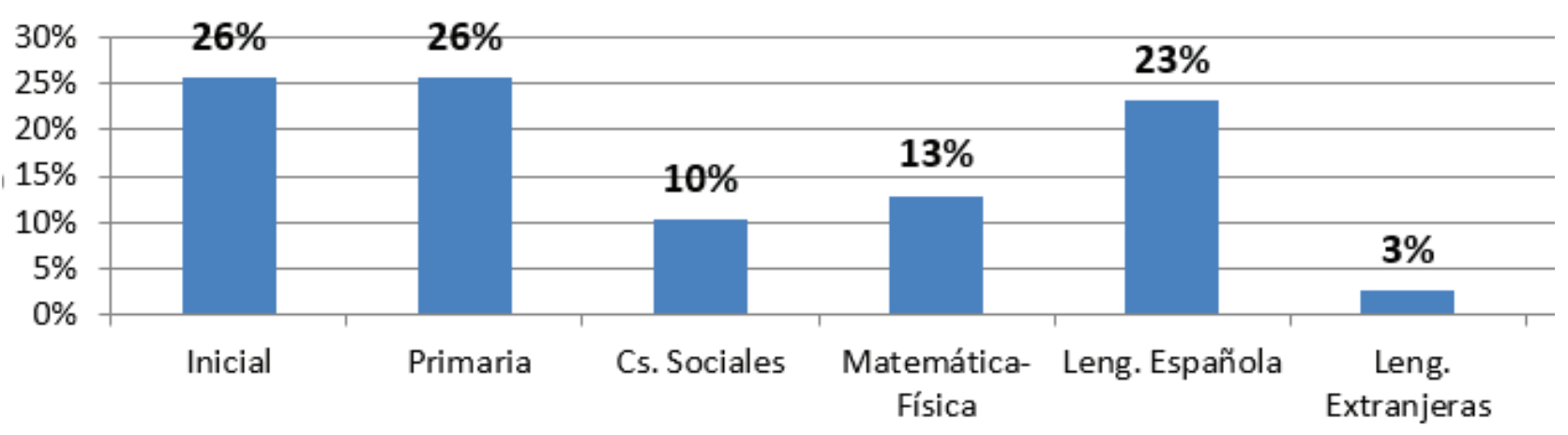


Los sujetos informantes fueron notificados previamente acerca del uso investigativo que se les daría a sus valoraciones, sin embargo, en la presentación de los resultados se garantizó el anonimato, tanto de ellos como de los docentes a los que hicieron alusión en sus comentarios. No se consideraron relevantes para los fines de esta investigación las variables de edad y género, ya que la única condición para participar era ser estudiante de la referida asignatura.

La estrategia que se utilizó para la recolección de informaciones fue la revisión y sistematización de las respuestas registradas en las asignaciones enviadas por los estudiantes a la Plataforma Moodle de la Universidad, como foros (García, 2018) y preguntas claves dentro de las actividades del curso. Además, se propició un encuentro presencial en el que se realizó un grupo focal para ampliar algunos elementos que se identificaron como claves en la plataforma. Por último, se recogieron las anotaciones realizadas por el docente-investigador en un registro anecdótico (Ramírez, 2017; Rivero, 2020 y Ortega et al., 2020), en el que se priorizaron opiniones y comentarios expresados de manera espontánea, y que complementaron las valoraciones hechas por los participantes en sus tareas en la plataforma y el grupo focal. La logística metodológica de recolección de información siguió la complementariedad de las fuentes para contrastarlas y reforzar la interpretación final (Blanco y Pirela, 2016).

El trabajo se fundamentó en crear espacios reflexivos que permitieran a los estudiantes analizar los rasgos característicos del docente. Para lograrlo se diseñaron actividades que promovieran la criticidad a partir de situaciones reales y recreadas, donde se visualizara la actuación de los profesionales de la educación en su rol formador, orientador y ejemplificador. Estas actividades fueron:
1. Un Cine Foro con la Película "El Profesor Holland", cuya finalidad fue analizar la actuación del docente en un contexto complejo, retador y expuesto a dilemas éticos (Herek, 1995).

En relación con el cine foro como actividad de aprendizaje, Alfaro (2017) plantea que:

Es un recurso educativo que se sirve de las sensaciones que provoca el séptimo arte para facilitar y enriquecer el diálogo entre el tema de estudio y los estudiantes, para fomentar la capacidad crítica y reflexiva ética frente a la temática y dilemas que él plantea. (p. 6)

Siguiendo la postura del autor, se diseñó la tabla 2 de análisis para recoger las reflexiones de los estudiantes respecto a la historia presentada en la película y establecer así una referencia de actuación docente.

Tabla 2

\section{Guía de análisis para el Cine Foro}

\begin{tabular}{|l|l|l|}
\hline $\begin{array}{l}\text { Vea la película El Profesor Holland y presente un análisis a partir del } \\
\text { siguiente cuadro: https://www.youtube.com/watch?v=a1Z36sWvA9s }\end{array}$ \\
\hline Aspectos & $\begin{array}{l}\text { ¿Qué se aprecia } \\
\text { en la película? }\end{array}$ & $\begin{array}{l}\text { ¿Qué te enseña } \\
\text { como docente } \\
\text { en formación? }\end{array}$ \\
\hline $\begin{array}{l}\text { 1. } \\
\text { Razones para Holland } \\
\text { decidir ser maestro. }\end{array}$ & \\
\hline $\begin{array}{l}\text { 2. } \\
\text { Actuaciones apegadica que evidencia el } \\
\text { Profesor Holland. }\end{array}$ & $\begin{array}{l}\text { Holland respecto a la } \\
\text { ética. }\end{array}$ & \\
\hline 3. & $\begin{array}{l}\text { Actuaciones del Profesor } \\
\text { Holland que podrían } \\
\text { reñir con la Ética del } \\
\text { docente. }\end{array}$ & \\
\hline 5. & $\begin{array}{l}\text { Actuaciones del Profesor } \\
\text { Holland que podrías } \\
\text { imitar como docente. }\end{array}$ & \\
\hline
\end{tabular}




\section{Foro Reflexivo}

En esta actividad los estudiantes debían situarse en un contexto evaluativo para enjuiciar las actuaciones de algunos docentes que habían tenido en su trayectoria estudiantil e identificar los procederes que consideraban éticos y los que estimaban éticamente inapropiadas. Tal como afirman Gutiérrez et al. (2009):

El modelo reflexivo en la formación de maestros debe favorecer una actitud indagadora en el futuro profesor que le lleve desde procesos introspectivos sobre su propia escolarización pretérita y su actual práctica docente a impulsar comunidades de aprendizaje desde una perspectiva crítica. (p. 496)

Las informaciones fueron categorizadas en matrices que permitieron organizar las opiniones de los participantes. Estas se muestran en los resultados como tablas 3 y 4 .

\section{Diarios Reflexivos "Un ejemplo a seguir"}

Los Diarios Reflexivos consistieron en producciones escritas asignadas a los estudiantes, en las que debían describir una actuación ejemplar de algún docente que les impactó positivamente en su formación. Esta actividad tenía la finalidad de provocar una evaluación de experiencia, en relación con el perfil que habían denotado en sus docentes durante su proceso formativo en la universidad. Algunas de esas experiencias se incluyen textualmente como una manera de mostrar los argumentos creados por ellos, respetando su autenticidad.

El análisis de toda la información recabada se realizó a partir de categorías emergentes surgidas de los argumentos de los estudiantes. Esto permitió encon- trar similitudes y diferencias en las perspectivas de los estudiantes, para interpretar y comprender la lógica personal y grupal de los mismos, acerca del perfil ético del docente universitario. Para ello, se construyeron tablas y figuras en correspondencia con los objetivos del estudio y se discutieron los aspectos de mayor relevancia, a través de la triangulación entre las opiniones de los estudiantes y la literatura consultada.

\section{Resultados}

El uso de las técnicas de recolección de informaciones favoreció la creación de espacios reflexivos que permitieron a los estudiantes de la carrera de Educación analizar los rasgos característicos del perfil ético del docente universitario.

A través del cine foro los estudiantes analizaron el personaje de la película como un posible referente de actuación ética, o ver oportunidades de mejora en sus acciones que se conviertan en alerta de actos a evitar durante su futuro ejercicio docente.

Por otro lado, en el foro reflexivo se situaron en un contexto evaluativo las actuaciones de los docentes que habían tenido en su trayectoria estudiantil universitaria, para identificar aquellas que consideraban éticas y las que estimaban éticamente inapropiadas.

De las 39 respuestas interpretadas, fueron incluidas las que coincidieron en más de un $50 \%$ de los planteamientos emitidos por estudiantes, es decir, en 20 o más de los comentarios recibidos de forma virtual o impresa.

La tabla 3 muestra las valoraciones manifestadas por los estudiantes acerca de las actuaciones consideradas éticamente correctas y deseables en sus docentes. 
Tabla 3

Rasgos éticamente correctos según los estudiantes

\begin{tabular}{|c|c|}
\hline \multirow{15}{*}{$\begin{array}{l}\text { Aspectos } \\
\text { éticamente } \\
\text { correctos en la } \\
\text { actuación de } \\
\text { los docentes: }\end{array}$} & a) Llegar puntualmente al salón de clases. \\
\hline & b) Saludar de manera cordial y sincera. \\
\hline & c) Mostrar interés por sus estudiantes. \\
\hline & $\begin{array}{l}\text { d) Preguntar por los estudiantes que no } \\
\text { asistieron a clase. }\end{array}$ \\
\hline & $\begin{array}{l}\text { e) Responder a las inquietudes de manera } \\
\text { directa y cortésmente. }\end{array}$ \\
\hline & $\begin{array}{l}\text { f) Si va a ausentarse del salón, notifica al } \\
\text { grupo. }\end{array}$ \\
\hline & $\begin{array}{l}\text { g) Realizar las correcciones de manera } \\
\text { cordial. }\end{array}$ \\
\hline & $\begin{array}{l}\text { h) Vestimenta es apropiada a su labor } \\
\text { educadora. }\end{array}$ \\
\hline & $\begin{array}{l}\text { i) Ser coherente respecto a lo que dice y lo } \\
\text { que hace. }\end{array}$ \\
\hline & $\begin{array}{l}\text { j) Mostrar compromiso con su formación y } \\
\text { actualización. }\end{array}$ \\
\hline & k) Ser entusiasta y motivador. \\
\hline & $\begin{array}{l}\text { 1) Evitar acercamiento excesivo con sus } \\
\text { estudiantes. }\end{array}$ \\
\hline & m) Ser justo en el proceso evaluación. \\
\hline & $\begin{array}{l}\text { n) Promover la democracia y la equidad en } \\
\text { el aula. }\end{array}$ \\
\hline & $\begin{array}{l}\text { n) Ser colaborador y solidario con sus } \\
\text { colegas y estudiantes. }\end{array}$ \\
\hline
\end{tabular}

Nota: elaboración propia a partir de los foros colocados en los cursos virtuales.

Desde otra perspectiva, los estudiantes consultados identificaron algunas actuaciones poco deseables en la actuación de un docente. En la tabla 4 se presentan las valoraciones predominantes en los comentarios de los 39 participantes.

\section{Tabla 4}

Rasgos éticamente no deseables según los estudiantes

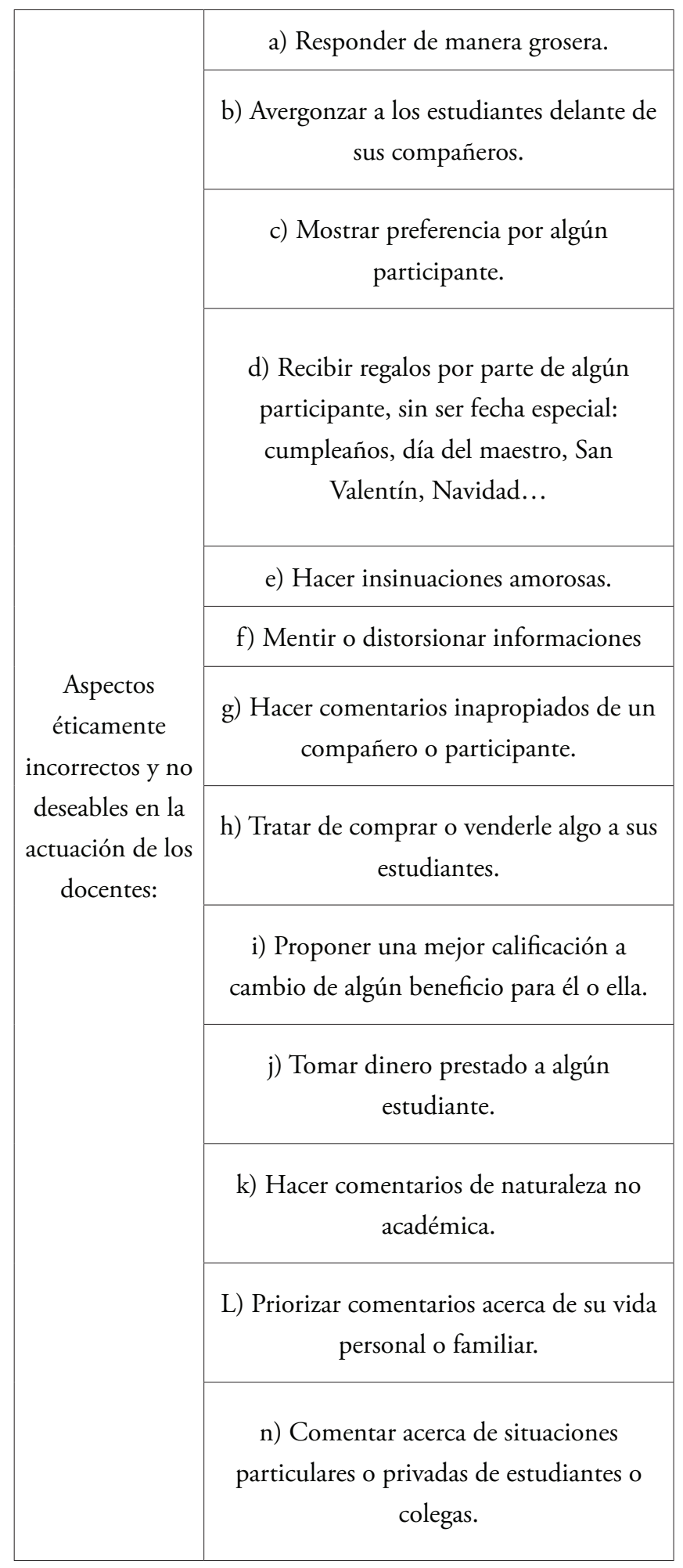

Nota: elaboración propia a partir de los foros colocados en los cursos virtuales. 
La práctica anterior favoreció en los estudiantes un espacio de deducción e inferencias para categorizar las actuaciones de los docentes universitarios que podrían identificarse como éticas y antiéticas. El ejercicio permitió situarse en un rol valorativo para establecer qué sería correcto e incorrecto en un formador a nivel superior.

En la actividad "Un ejemplo a seguir", quienes participaron se sintieron retados a identificar y describir una actuación ejemplar de algún docente que les impactó positivamente en su formación. De los 39 comentarios, se asumieron 10, considerando los primeros 5 recibidos en la asignación y los últimos 5. En este foro virtual se destacaron, entre otros, los siguientes testimonios (expresiones textuales):

Para la participante 1:

El docente A es respetuoso, honesto, empático y amistoso con sus estudiantes. Además, es motivador y siempre me califica con justicia y honestidad, sabe entender el alumno y ponerse en su zapato o situación. Lo considero como el docente más humilde y honesto de la universidad.

La misma participante expresa que:

También considero a la maestra $B$, como un verdadero ejemplo ético en la profesión docente, ya que una vez tuve una situación con una calificación final de la asignatura Geografía Dominicana II , yo muy decente le escribi que cuál era el motivo de tan baja calificación si estaba excelente en la plataforma y me habia ido bien en el examen, esta maestra observó la situación y me dijo que habia tenido un error al calificar, que mi puntuación era 95, me mandó directamente a revisión y me arregló mi calificación, fue una maestra muy justa y responsable al asumir su error.

En el mismo sentido, se presenta otro testimonio significativo, compartido por la participante 2 , en el que describe una experiencia relevante al cursar una asignatura en la Universidad y que involucra la actuación de una docente. Así lo planteó:

Una compañera tenía tres ausencias, como sabemos pierde el derecho a la prueba escrita, pero ella llegó y se sentó a tomar su examen. La facilitadora $C$, cuando pasó la lista se dio cuenta de la situación y se le acercó a decirle que no podia tomar el examen y ella comenzó a decirle palabras inapropiadas, pero la profe mantuvo su postura y nunca faltó a sus cualidades éticas, intentó provocarla de diferentes maneras, pero ella siempre la evadía hasta que desistió y no le quedó más nada que salir del aula. Todos nos quedamos asombrados porque lo que ella le decía, imagino que otra persona hubiera perdido la postura. Para mi ese fue un gran ejemplo ético.

Los testimonios presentados anteriormente, evidencian el compromiso, responsabilidad y sensibilidad humana en la actuación de los docentes. Muestran el celo por cumplir con las normativas institucionales, sin perder la empatía y respeto por sus estudiantes.

El participante 3 manifestó que:

El maestro D, es un docente que siempre llega a las aulas de la Universidad con su mejor cara, se preocupa por cómo están sus estudiantes, siempre se interesa por el aprendizaje de sus alumnos, es un maestro que no le molesta explicarte dos y tres veces un tema, para que puedas entender y comprender. El facilitador $D$ es un profesor que entiende la situación de cada estudiante, y si quizás por alguna situación de la vida no pudiste cumplir con una tarea asignada, él se interesa en saber tu situación y siempre busca solución a esas dificultades.

También es un docente que cuando eres muy activo en las calificaciones de las tareas y él ve que estás sacando notas bajas, te llama en privado para saber por qué el cambio. Cuando te tiene que corregir algo, lo hace en privado y eso es algo que lo enaltece mucho. Considero que sus actuaciones son apegadas a la ética.

Esta experiencia es descrita por el participante 4: Hace como un año cuando empecé la carrera, en una asignatura con la docente E, dije algo que no tenía fundamento, ella esperó que todos salieran y me dio un gran consejo, que nunca olvido, ella me dijo: ...madura, que tus palabras sean más profundas que tus acciones.

El participante 5 plantea este ejemplo de actuación ética en un docente universitario:

En una clase con el profesor $F$, de Matemáticas, una estudiante se acercó a él a conversar sobre una problemática que ella estaba presentando. Mi compañera 
se atrasaba en sus tareas, habia faltado dos veces y se notaba distante.

Ese día, ella se acercó al profesor a mitad de la clase y le pidió salir al pasillo. Al parecer conversó con el profesor sobre su situación y volvieron ingresar al salón. Cuando la clase terminó, (casualmente ese día me quedé recogiendo unos equipos que habiamos usado) otra chica que pertenecía al grupo de la compañera con problemas se acercó con una actitud un poco altanera a preguntarle al profesor qué le habia dicho ella y qué iba a hacer él, con respecto con ella.

El profesor, muy calmadamente le contestó que se habia tratado de asunto totalmente discreto entre ellos y él como docente y que no debia divulgar esa información a un tercero, que él entendía también la condición bumana de cada uno de sus alumnos y que ella por igual debia hacerlo como compañera.

Ese día me sentí honrado de dar clase con él, porque entendi que era muy empático con nosotros $y$, sobre todo, en clases posteriores, se pudo notar un cambio positivo en la compañera que tenía problemas.

En este testimonio el participante 6 refiere: Hace tres años y ocho meses, entré a la universidad, cuando cursaba el segundo cuatrimestre, la universidad desarrolló el primer Seminario Internacional de Educación, pero yo no tenía los recursos en ese momento para ir al seminario, pero por mi situación me daba vergüenza decirlo.

Como uno siempre tiene una o un compañero en quien confiar, le conté lo que me pasaba a mi amiga, ésta se acercó a la maestra $G$, y le explicó.

La profesora, para mi, es un gran ejemplo ético, pues ella supo ponerse en mi lugar, supo entender $y$ buscar una mejora para mi situación. Entre ella y mis compañeros se compusieron y me recolectaron el dinero de ir al seminario, es algo que nunca olvidaré, pues me dio una gran lección de vida, ya que entendí que el docente debe de ser flexible y ser como un espejo para cada uno de sus alumnos.
En las vivencias descritas anteriormente se puede corroborar el interés que muestran los docentes por las necesidades de sus estudiantes. De igual manera, es evidente la solidaridad y discreción para atender esas necesidades. Otro testimonio dado señala lo siguiente:

Recuerdo que cuando cursaba la asignatura Didáctica General con el facilitador $H$, presenté un problema de salud (comienzo de un preinfarto produciendo una parálisis facial), no podía utilizar la PC para hacer mis asignaciones, ya que mi estado de salud me lo impedia.

Luego de dos semanas hablé con el profesor donde retiraría la asignatura por las razones ya mencionadas, él que para muchos era un profesor muy exigente, me dijo lo siguiente: no vas a retirar la materia, realiza las tareas como puedas, si se cierran en plataforma, tienes la opción de enviarla a mi correo, cójalo suave, su salud es lo más importante en este momento.

Como soy una persona muy sentimental lloré y él me dijo que no me preocupara que todo estaría bien, confié en sus palabras, y de verdad que agradezco infinitamente ese gesto que él tuvo conmigo. Lo considero como un verdadero ejemplo ético, ya que manifestó una gran empatía ante la situación que presentaba, y me ayudó a salir adelante a pesar de mi condición de salud. Así lo cuesta el participante 7.

La participante 8 presenta una vivencia como estudiante de la modalidad virtual:

Siempre he sido estudiante virtual, y haber tomado varias materias con la maestra I, fue de mucha satisfacción, ya que ella muestra afecto hacia sus alumnos $e$ interés en el proceso de enseñanza-aprendizaje. En una ocasión tenía confusión en una tarea y esta docente me llamó de su celular para explicarme y aclárame las dudas que tenía, se portó con mucha amabilidad y respeto, a pesar de nunca haberme visto personalmente en un aula. Esto me dejó una imagen muy bonita de esta maestra y a pesar de no conocerla personalmente, la recuerdo siempre como una excelente maestra. 
Con la participante 9 se recoge esta experiencia: Al principio de la carrera tenía matemáticas, pero hacía muchos años sin estudiar, asi que estaba un poco oxidada con las matemáticas; pero la maestra que tenía en ese momento me llamó, le expliqué mi situación y se ofreció a darme clases vía Skype para que yo pudiera entender mejor y aprobar la asignatura. Para mi esta profesora marco mi vida y mi forma de ver la docencia.

Finalmente, la participante 10 cuenta:

Considero como un verdadero ejemplo ético en la profesión docente a la facilitadora J, quien siempre saluda con empatía a sus estudiantes, también nos orienta y nos cuenta como ser mejores docentes en un futuro.

Una vez falté a la universidad ya que estaba mal de saludy los muchachos en el grupo de WhatsApp dijeron que ella preguntó por mí, luego el sábado siguiente cuando llegué al aula me abordó para preguntarme por mi salud y ella dijo que se extrañó ya que yo era muy responsable, me hizo sentir muy bien su comentario y la forma en que me trató, para mi es una de las mejores facilitadoras que se encuentran en UAPA.

Estos testimonios dan cuenta de actuaciones éticas de mucha significación para los estudiantes. De acuerdo con sus argumentos han calado en su proceso formativo, permitiéndoles afianzar el perfil que debe mostrar un verdadero docente.

$\mathrm{Al}$ revisar las repeticiones en las opiniones y comentarios enviados por los 39 estudiantes que participaron voluntariamente, se presentan a continuación las coincidencias encontradas respecto a actuaciones de sus docentes que consideraron importantes y ejemplificadoras en su futura actuación profesional. Estas valoraciones han sido agrupadas en tres categorías del ámbito de actuación docente: Trato hacia los estudiantes, Manejo en la docencia y Cumplimiento institucional, presentando solo los postulados que coincidieron en 10 o más comentarios.

\section{Tabla 5}

\section{Coincidencias respecto a rasgos éticos del docente}

\begin{tabular}{|c|c|c|}
\hline $\begin{array}{l}\text { Ámbito de } \\
\text { actuación }\end{array}$ & Planteamientos de los estudiantes & Coincidencias \\
\hline 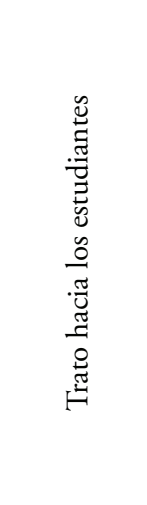 & $\begin{array}{l}\text { "respetuoso, honesto, empático y } \\
\text { amistoso". } \\
\text { "se preocupa por cómo están sus } \\
\text { estudiantes." } \\
\text { "llama la atención en privado". } \\
\text { "ponerse en mi lugar, supo } \\
\text { entender". } \\
\text { "me ayudó a salir adelante". } \\
\text { "se portó con mucha amabilidad y } \\
\text { respeto". } \\
\text { "saluda con empatía a sus } \\
\text { estudiantes". }\end{array}$ & $\begin{array}{l}31 \\
10 \\
14 \\
19 \\
13 \\
26 \\
28\end{array}$ \\
\hline 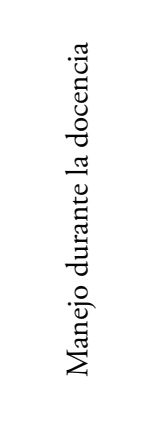 & $\begin{array}{l}\text { "califica con justicia y honestidad". } \\
\text { "no le molesta explicarte dos y tres } \\
\text { veces un tema". } \\
\text { "muestra afecto hacia sus alumnos". } \\
\text { "interés en el proceso de enseñanza- } \\
\text { aprendizaje". } \\
\text { "se detuvo explicarme y aclárame } \\
\text { dudas que tenía". } \\
\text { "nos orienta y nos cuenta como ser } \\
\text { mejores docentes en un futuro". }\end{array}$ & $\begin{array}{l}24 \\
27 \\
11 \\
16 \\
18 \\
23\end{array}$ \\
\hline 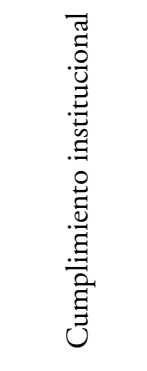 & $\begin{array}{l}\text { "llega a tiempo y respeta el horario } \\
\text { de las clases". } \\
\text { "Acudió a la revisión de } \\
\text { calificaciones". } \\
\text { "reporta las calificaciones siguiendo } \\
\text { el calendario". } \\
\text { "orienta acerca de las circulares } \\
\text { enviadas por la universidad". }\end{array}$ & $\begin{array}{l}35 \\
10 \\
17 \\
15\end{array}$ \\
\hline
\end{tabular}

Nota: elaboración propia a partir de los foros colocados en los cursos virtuales.

Para identificar los calificativos claves que, según los criterios de los estudiantes deben evidenciar los docentes universitarios, se utilizó una herramienta denominada "nube de palabras", un recurso útil para visualizar la agrupación de palabras que se repiten 
con mayor frecuencia en un texto. En la figura No. 2 se recogen los adjetivos que más coincidieron en los comentarios de los estudiantes, al describir el perfil ético de un docente.

\section{Figura 2}

Calificativos de un docente ético

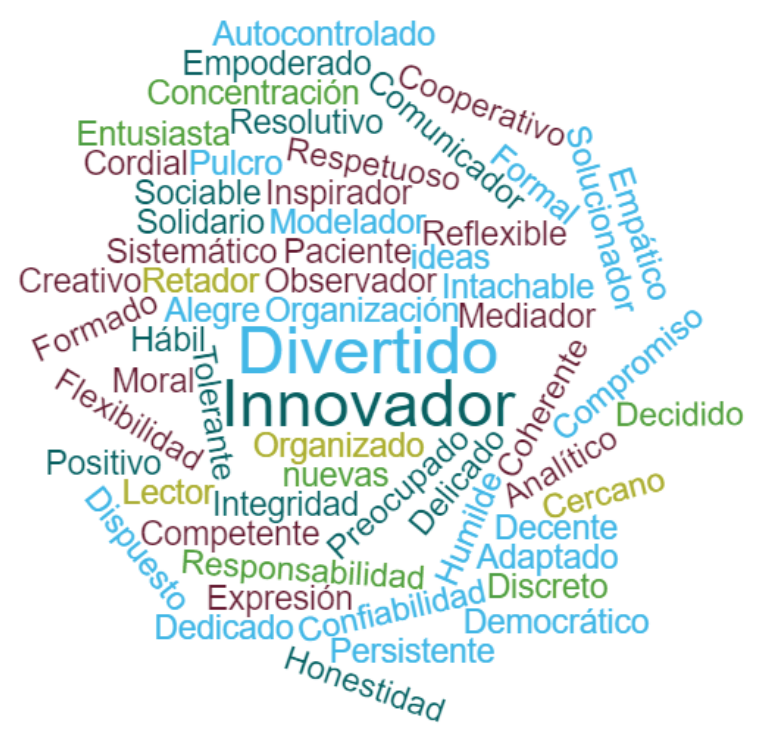

Nota: elaboración propia a partir de los foros colocados en los cursos.

\section{Conclusiones}

El estudio se propuso comprender, desde el punto de vista de un grupo de estudiantes de educación, los rasgos más importantes del perfil ético de un docente universitario, así como caracterizar, según los estudiantes y su experiencia, las actuaciones que consideraban antiéticas en el proceder de un docente universitario.

$\mathrm{Al}$ interpretar las experiencias de los estudiantes acerca de las actuaciones éticas de docentes que han impactado positivamente en su formación, se llegó a las siguientes conclusiones:

La investigación permitió a los estudiantes identificar los rasgos del perfil ético de un docente universitario, destacándose aspectos vinculados a la puntualidad, cordialidad, buen trato hacia los estudiantes, actuación profesional coherente entre lo que dice y hace, justicia, solidaridad y democracia en el salón de clases y actualización constante. Esto coincide con Merellano et al. (2016), quienes realizaron un estudio de caso con estudiantes de la Facultad de Educación de la Universidad Autónoma de Chile, sede Talca, en el que recogieron como cualidades éticas que los docentes universitarios deben evidenciar: compromiso con la labor pedagógica, puntualidad, presentación personal y coherencia. De acuerdo con los estudiantes consultados, un bueno docente debe ser una persona confiable, sociable, cercana, íntegra, empática, colaborativa, comprensiva, segura, paciente, humilde, alegre y respetuosa.

Igualmente, en el estudio realizado por Chávez y Benavides (2011) en la Universidad Nacional Autónoma de México, se destaca la relevancia de los estudiantes en la labor formadora y el compromiso ético del docente, enfatizando que son los beneficiarios o perjudicados de la puesta en práctica de los cambios educativos que el profesor debe representar. Estos aspectos reafirman la responsabilidad del docente universitario como agente motivador y propulsor de los cambios sociales. En ese sentido, Panza (2020) considera que el docente universitario posee la capacidad de transformar su entorno y enriquecer la condición humana de sus estudiantes.

En esa misma perspectiva, pero en el contexto nacional, Belando y Tavárez (2017) estudiaron el perfil del docente en la educación universitaria de República Dominicana, manifestando que los docentes evidencian necesidades y limitaciones tanto en lo personal como en lo profesional y reconocen los retos actuales para el cambio. También destacan aspectos importantes que dan cuenta de la cercanía, buen trato hacia los estudiantes y entusiasmo, además de valores como la responsabilidad, la puntualidad y el compromiso social.

Es importante destacar que el contexto e idiosincrasia cultural en que convergen los estudiantes pueden incidir en la valoración que estos tengan del perfil ético de sus docentes como referentes de actuación. Tal es el caso estudiando por Martín et al. (2014) el que los estudiantes preuniversitarios de cuatro universidades españolas prefieren un profesor universitario que destaque en ciertos aspectos profesio- 
nales más que en cualidades personales. Sin embargo, Villarroel y Bruna (2017) realizaron una investigación en la Universidad del Desarrollo en Chile, en la que los estudiantes consultados manifestaron que la competencia más esperada en sus docentes era la accesibilidad, entendida como la cercanía, empatía, flexibilidad, humildad y disponibilidad, seguida por la actualización del conocimiento.

A pesar de la divergencia que pueda darse en la valoración del perfil ético por parte de sus estudiantes, Rodríguez (2020) entiende que cada día sigue tomando mayor importancia el reconocimiento de las competencias blandas en desempeño del docente universitario, especialmente la responsabilidad.

Los estudiantes, a partir de reflexiones valorativas, lograron especificar las actuaciones que pueden ser consideradas antiéticas en el proceder de un docente universitario, dentro de las cuales resaltaron: responder de manera grosera, mostrar preferencia por algún estudiante, mentir, hacer insinuaciones amorosas, hacer comentarios negativos sobre cualquier miembro de la comunidad universitaria e involucrarse en algún negocio con sus estudiantes.

Un panorama similar a lo referido anteriormente, lo deja ver Izarra (2016), en un trabajo realizado con profesores que cursaban estudios de posgrado en educación, en tres instituciones universitarias del estado Táchira, Venezuela, en el que concluye que:

Es necesario repensar la formación en valores de los docentes, pues ésta es la mejor manera de garantizar que tal cuestión se asuma como una labor inherente a la práctica pedagógica, el maestro debe experimentar de forma consciente estrategias, $y$ debe creer que es posible contribuir efectivamente en la formación en valores de sus propios estudiantes. (p. 27)

Las prácticas desarrolladas en este estudio permitieron a los estudiantes describir actuaciones éticas de sus docentes que les han impactado positivamente como futuros maestros y de acuerdo con sus argumentos, por lo tanto, han influido en su proceso formativo, permitiéndoles afianzar el perfil que debe mostrar un verdadero docente del siglo XXI. Lo mismo recogen
Aguirre y De Laurentis (2016), al indagar en la cuestión de la buena enseñanza de los docentes universitarios a partir de los retazos narrativos de los estudiantes avanzados del profesorado en Historia en la Universidad Nacional de la Plata, Argentina, quienes refieren: "En lo que respecta específicamente a sus cualidades morales, la mayoría de los estudiantes destacó el compromiso, el respeto, la responsabilidad, la dedicación, y la pasión" (p. 151). De igual manera, destacan que "la ética, el intelecto, el afecto, el compromiso y la pasión conforman, para los alumnos, las características centrales de aquellos docentes memorables que han pasado por sus vidas" (p. 152).

Este estudio pone de manifiesto la relevancia de prestar atención a los estudiantes con relación al tipo de docente que anhelan y demandan, específicamente en lo relacionado al marco actitudinal. Estos rasgos guardan relación con los requerimientos del perfil ético del docente de la educación superior que plantean diversos autores consultados (Vargas y Carrasquero, 2017; Quintana, 2016; Merellano et al., 2016; Hernández y Olivo, 2020; INTEC, 2016)

La investigación muestra que los docentes de la UAPA poseen alta valoración por parte de sus estudiantes. Esta situación debe ser considerada para que persista y se tenga presente en los programas de evaluación del desempeño docente, así como en los programas de inducción de los nuevos maestros.

\section{Referencias}

Aguirre, J. y Laurentis, C. de. (2016). La buena enseñanza de los docentes universitarios desde la perspectiva de los estudiantes: Combinación de formación profesional y valores morales. Entramados: educación y sociedad, O(3), 135-141.

Alfaro-Reyes, F. (2017). El Cine Foro Como Herramienta Pedagógica. Consejo Nacional para igualdad de género. https://cutt.ly/xjj9Znn

Alix, A. (2017). Propuesta de un plan de formación y desarrollo profesional del profesorado de la UPEL-IPC en el ámbito de la transformación universitaria. Revista Educación Superior y Sociedad (ESS), 19(19), 207-232. 
Baena-Paz, G. (2017). Metodología de la Investigación (Tercera edición). Ciudad de México: Grupo Editorial Patria. https://cutt.ly/rjj9Vyk

Belando-Montoro, M. R. y Tavárez-Marzán, M. T. (2017). El perfil del docente en la educación universitaria de República Dominicana. Experiencia de una colaboración Erasmus Mundus entre la UCM y la UASD. IJERI: International Journal of Educational Research and Innovation, (7), 164-185.

Blanco, N. y Pirela, J. (2016). La complementariedad metodológica: Estrategia de integración de enfoques en la investigación social. Espacios públicos, 19(45), 97-111.

Chávez-González, G. y Benavides-Martínez, B. (2011). Los profesores universitarios: Entre la exigencia profesional y el compromiso ético-social. Sinéctica, (37), 1-13.

Colina Vargas, A. M. y Vargas de Carrasquero, I. C. (2018). La ética del docente investigador y sus principios. Revista Cientifica Ecociencia, 4(5), $1-19$.

Crisol, M. y Romero M. (2014). Práctica docente versus ética docente. Hacia la mejora de la práctica docente a partir de la ética profesional. Journal for Educators Teachers and Trainers, 5(2), 23-35.

Denzel, N. y Norman, Y. (2012). El campo de la Investigación Cualitativa (Manual de Investigación Cualitativa I). Editorial Gedisa.

Díaz-Herrera, C. (2018). Investigación cualitativa y análisis de contenido temático. Orientación intelectual de revista Universum. Revista General de Información y Documentación, 28(1), 119-142. https://doi.org/10.5209/RGID.60813

García, B. E. (2018). La interacción colaborativa en los foros virtuales de un curso de posgrado de la Universidad Nacional de San Luis. Biblioteca De Trabajos Finales, 1(2), 1-152.

Gutiérrez Cuenca, L. P., Correa Gorospe, J. M., Jiménez de Aberasturi Apraiz, E. e Ibáñez Etxeberria, A. (2009). El modelo reflexivo en la formación de maestros y el pensamiento narrativo: Estudio de un caso de innovación educa- tiva en el Practicum de Magisterio. Revista de educación, (350), 493-505.

Herek, S. (1995). Profesor Holland Triunfo a la vida. [Pelicula]. Hollywood Pictures.

Hernández-Sampieri, R., Fernández-Collado, C. y Baptista-Lucio, P. (2014). Metodología de la investigación. McGraw Hill Interamericana.

Instituto Tecnológico de Santo Domingo (INTEC). (2016). Reglamento del personal académico. https://cutt.ly/kjj986N

Izarra-Vielma, D. A. (2016). Experiencias para la formación en valores de docentes estudiantes de posgrado. Experiencias y perspectivas en ética profesional y responsabilidad social universitaria en Iberoamérica. Universidad Pedagógica Experimental Libertador.

Martín, S. S., Santamaría, M., Hoyuelos, F. J., Ibáñez, J. y Jerónimo, E. (2014). Variables definitorias del perfil del profesor/a universitario/a ideal desde la perspectiva de los estudiantes pre-universitarios/as. Educación $X X 1,17(2)$. https:// doi.org/10.5944/educxx1.17.2.11486

Merellano-Navarro, E., Almonacid-Fierro, A., Moreno-Doña, A. y Castro-Jaque, C. (2016). Buenos docentes universitarios: ¿Qué dicen los estudiantes? Educação e Pesquisa, 42(4), 937-952. https://doi.org/10.1590/s1517-9702201612 152689

Ministerio de Educación de la República Dominicana. (2015). Perfiles Docentes.

Ortega-Bravo, B. H., Briones-Ordóñez, O. V., Campoverde-Tabara, L. M. y Ríos-Mera, N. P. (2020). Espacios verdes que caracterizan el paisaje natural del Campus Central de la UTM en la Ciudad de Portoviejo. Polo del Conocimiento, 5(5), 333-344. https://doi.org/10.23857/pc. v5i5.1426

Ortiz, L. A. (2020). Evaluación de Desempeño como Factor Estratégico para Rendimiento Académico del Docente Universitario. Revista Scientific, 5(15), 336-349. https://cutt.ly/Bjj3aae

Panza, N. (2020). Docente universitario, alfarero de vidas... Revista Tecnológica-Educativa Docentes 2.0, 8(1), 60-65. 
Pérez-Gómez, Á. I. (2019). Ser docente en tiempos de incertidumbre y perplejidad. Márgenes, Revista de Educación de la Universidad de Málaga, 3(17). https://doi.org/10.24310/mgnmar.v0i0.6497

Quintana, O. (2016). Deontología del docente, formador de formadores, en el subsistema de Educación universitaria, en su rol investigador. Revista ARJÉ, 10(19). https://cutt.ly/9jj3gEt

Ramírez-Núñez, K. V. (2017). El registro anecdótico en la evaluación formativa oral del idioma inglés [Título de Licenciada en Ciencias de la Educación. Mención Inglés, Universidad Central del Ecuador]. https://cutt.ly/ojj3ev4

Rivero-Hernández, M. (2020). El Protocolo o Proyecto de investigación. Universidad La Salle.

Rodríguez-Siu, J.L. (2020). Las habilidades blandas como base para el buen desempeño del docente universitario. INNOVA Research Journal, ISSN 2477-9024 (Mayo-Agosto 2020). 5(2) 186-199. https://cutt.ly/Bjj3ksM

Rubio-Hernández, F. J. y Olivo-Franco, J. L. (2020). Dificultades del profesorado en sus funciones docentes y posibles soluciones. Un estudio descriptivo actualizado. Ciencia y Educación, 4(2), 7-25. https://doi.org/10.22206/cyed.2020. v4i2.pp7-25
Santos, M. (2018). Un ramo de flores para los docentes del mundo. Editorial Homo Sapiens.

Universidad Abierta para Adultos (UAPA). (2009). Modelo Educativo por Competencias centrado en el aprendizaje MECCA. Editora Buho.

Universidad Abierta para Adultos (UAPA). (2014). Reglamento de Facilitadores y Carrera Docente. https://cutt.ly/njj3QWJ

Villarroel, V. A. y Bruna, D. V. (2017). Pedagogical competencies of university teachers: A case study, which incorporates the perspective of chilean teachers and students. Formación universitaria, 10(4), 75-96.

Zepeda, R. A. y Hernández, M. M. V. (2020). Hacia la definición conceptual del constructo Calidad de la Educación Superior en el contexto de la Universidad Nacional Agraria. Revista Educación, 298-312. https://doi.org/10.15517/revedu. v44i2.40522 